\section{Guido Orlandini}

Received: 23 June 2001

Accepted in revised form: 24 August 2001

G. Orlandini ( $\triangle)$

Pain Theraphy and Palliative Care Center

Hospital of Tortona

Tortona (AL), Italy

e-mail: orlandiniguido@asl20.piemonte.it

Tel.: +39-0131-865361

Fax: +39-0131-865403

\section{Choice of open or percutaneous procedures in the surgical treatment of trigeminal neuralgia}

Indeed, angiography and computed tomography showed the neurovascular contact but not the size of compression. Fortunately, today magnetic resonance imaging is a reliable instrument to ascertain NVC. So, the diatribe between the supporters of percutaneous techniques and MVD can be concluded with the following: (1) percutaneous techniques are indicated for patients without demonstrated NVC (including patients with $\mathrm{TN}$ in multiple sclerosis) and in those with NVC if MVD is contraindicated by ill-health or refused by the informed patient; and (2) MVD is indicated for patients with ascertained NVC who are in good health and who, informed of the surgical risk, favor this operation desiring no sensory deficit.

Key words Trigeminal neuralgia • Neurovascular conflict • Trigeminal percutaneous radiofrequency thermorhizotomy $\cdot$ Microvascular decompression

\section{Introduction}

Trigeminal neuralgia (TN) can be managed by medical and surgical treatment. Half of the patients are cured by drugs (particularly carbamazepine) without side effects, $25 \%$ are cured but have intolerable side effects and $25 \%$ are not cured [1]. Then, half of the patients require surgical treatment. When drugs become ineffective or not tolerated, the question of which intervention (percutaneous or open) is appropriate becomes an important issue. Among modern operations, three are percutaneous (trigeminal percutaneous 
radiofrequency thermorhizotomy (TPRT) [2], retrogasserian glycerol injection (RGI) [3] and percutaneous compression of the trigeminal ganglion (PCTG) [4]) and two are open (partial sensory rhizotomy (PSR) [5] and microvascular decompression (MVD) [6]).

The debate between the supporters of open techniques (particularly MVD) [7-14] and of percutaneous techniques (particularly TPRT) [15-24] has lasted many years. The former sustain that MVD is the "definitive physiologic rather than symptomatic operative treatment of patients with trigeminal neuralgia" [25] and the only non-destructive surgical treatment which produces pain control without sensory impairment nor postoperative dysesthesia [26, 27]. The latter point out that TPRT avoids the risks of craniectomy, it is repeated easily if tic pain recurs, morbidity is minimal and there is essentially no risk of mortality. Burchiel et al. [28] sustained that MVD should be considered because it attacks what is believed to be the primary etiology of tic douloureux, the trigeminal nerve is preserved, postoperative pain relief does not depend upon the production of sensory deficit and it may have a greater potential to produce long-lasting pain relief. Möbius et al. [29] affirmed that MVD should especially be recommended for patients in whom all other forms of therapy including TPRT have failed. Walchenbach et al. [30] stated that as neither TPRT nor MVD is an unequivocally more effective treatment, the less invasive procedure should be preferred. Morley [31] put the question if "it is justified to place the patient at a $1 \%$ risk of death and a $10 \%$ risk of significant, sometimes grave morbidity for the treatment of a condition that is never fatal when other procedures are available that are effective and carry virtually no risk of death or neurologic morbidity other than planned sensory impairment". Soyka [32] affirmed that the principle of MVD is either an interruption of the pain-conducting fibers or a nonspecific manipulation at the gasserian ganglion or the sensory root with the result of an interruption of abnormal ephapses and short-circuits and that the operation should not be considered to be a specific and causal therapeutic approach as well as the therapy of first choice for all cases. Taha and Tew $[33,34]$ affirmed that TPRT is the procedure of choice for most patients undergoing first surgical treatment and that MVD is recommended for healthy patients who desire no sensory deficit. On the contrary, Kunze and Steiner [9] affirmed that in every case of typical TN there is an indication for MVD, provided that pharmacotherapy has proved ineffective and anesthesia carries no increased risk due to old age or ill-health. For patients under 65 years, Broggi et al. [35] proposed PCTG or, if neuroradiological evidence of neurovascular conflict (NVC) is given, MVD; for patients older than 65 years, these authors proposed TPRT.

Considering these different opinions and the lack of firm evidence for choosing the surgical treatment, the aim of this study was to define criteria for the selection of patients under- going percutaneous or open operations through an up to date review of the literature on the outcome of TPRT (the more classic percutaneous surgical treatment of TN) and MVD.

\section{Materials and methods}

Out of all published reports of patients treated by TPRT or MVD, papers with an average follow-up of 3 years or longer were selected. According to this criterium, 18 studies including $7473 \mathrm{TN}$ patients treated by TPRT (Table 1) with a follow-up from 3 to 9.3 years (average 5.8 years) and 17 studies including 3611 patients treated by MVD (Table 2) with a follow-up from 3 to 8.5 years (average 5 years) were considered. The results are indicated as the average of the values of the different papers.

\section{Results}

Immediate pain relief was achieved in $92.5 \%$ of patients treated with TPRT and $90.4 \%$ of patients undergoing MVD. Relapses of pain were observed in $24.4 \%$ of TPRT cases and in $21 \%$ of MVD cases. The predictable postoperative pain relief examined with the Kaplan-Meier plot [36] showed a half-life of 3 years [37], 5 years [38] or more than 5 years [39] for TPRT and of 10 years [40] for MVD. Facial sensory deficit was a common and wanted finding in TPRT cases and an unwanted remark in $8.9 \%$ of MVD cases.

Dysesthesia was reported by $15.6 \%$ of patients treated by TPRT: it was mild (non-disturbing and non-requiring treatment) in $7.9 \%$ of cases, moderate (disturbing but controlled by drugs) in $5.9 \%$ and severe (disturbing and not controlled by drugs) or anesthesia dolorosa in $1.8 \%$. In MVD-treated patients, dysesthesia was not quoted among the complications.

Motor deficits figured in $7.3 \%$ of patients treated with TPRT. Damage to cranial nerves other than $\mathrm{V}$ figured in $0.4 \%$ of TPRT cases (particularly, IV and VI with transient diplopia) and in $7.4 \%$ of MVD cases (particularly, VII and VIII with bradyacusia or deafness).

Fritz et al. [41] observed that out of 21 patients examined audiometrically before and after MVD, five (23.8\%) had postoperative hearing impairment. Fuse and Miller [42] observed a delayed and progressive hearing loss after MVD, which they interpreted to be the result of reactive scar tissue and atrophy of the auditory nerve. Vestibular nerve injuries were also described [43] and, moreover, peduncular hallucinosis $[44,45]$.

Other possible major neurological complications after MVD are: cerebellar hemorrhage, edema or infarction, arterial air embolism, acute mental status change, status epilepticus, acute epidural hematoma, chronic subdural hematoma, 


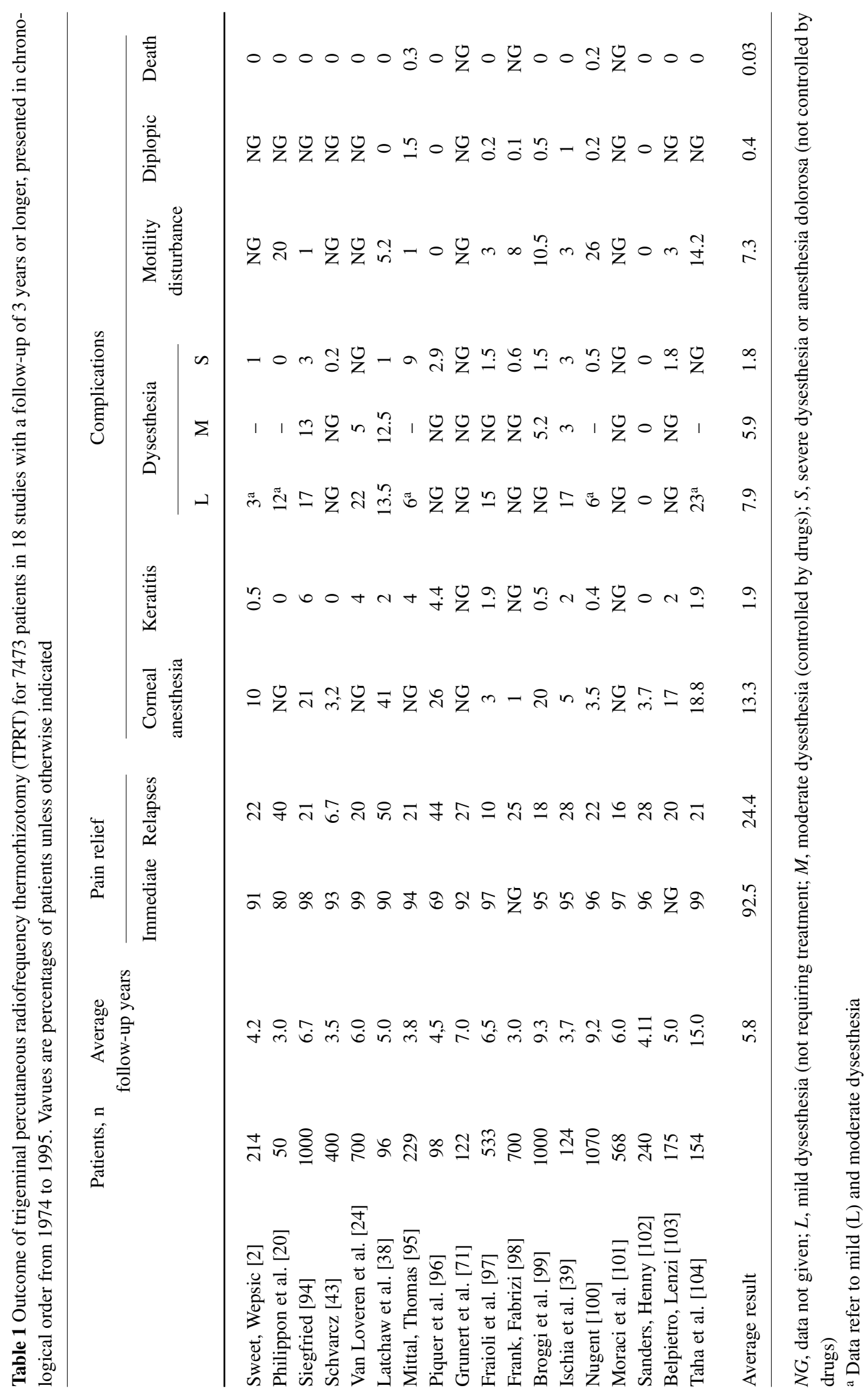




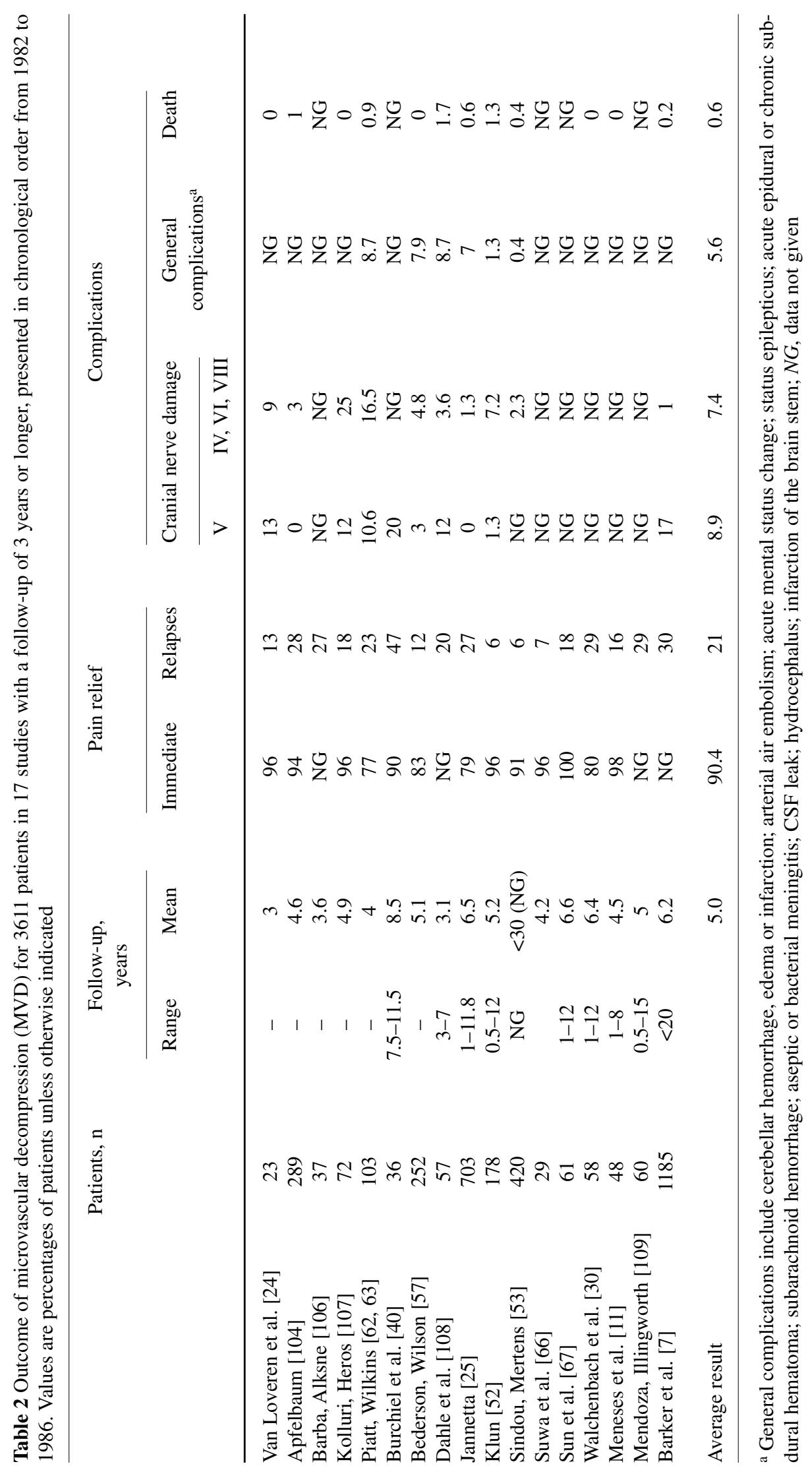


subarachnoid hemorrhage, aseptic or bacterial meningitis, cerebrospinal fluid leak (CSF) leak, hydrocephalus and infarction of the brain stem. Finally, operative death occurred in $0.03 \%$ and $0.6 \%$ of patients undergoing TPRT and MVD, respectively.

Considering the outcome of TPRT and MVD in multiple sclerosis-related TN (MS-TN), Siegfried [46] affirmed that pain can be successfully eliminated by operation. Brisman [47] found that the probability of recurrence showed no significant differences in 16 patients with MS-TN compared with 219 patients without MS. Only Broggi and Franzini [48] observed a high recurrence rate in the MS-TN group (40\% at 1-4 years of follow-up). On the other hand, Resnick et al. [49] affirmed that MVD fails to provide adequate or reliable pain relief in MS-TN.

\section{Discussion}

TPRT, the selective thermolesion of the trigeminal ganglion and root, has the faculty to control preoperatively by electrostimulation the trigeminal division(s) involved and, to some extent, to modulate the lesion itself in order to have hypalgesia or analgesia without anesthesia. On the other hand, MVD, which is not a neurolesive operation, consists of the separation of the retrogasserian root away from the impinging vessel using an interposed foreign body or by the transposition of vessel without interposition of synthetic material [50]. The operation is based on the assumption that $\mathrm{TN}$ is caused by NVC.

The average immediate postoperative pain relief and long-term recurrence are the same for TPRT and MVD. For both operations, the percentage of recurrence is different in the various series. The different percentages of recurrence after TPRT (from 6.7\% in the paper of Schvarcz [43] to 50\% in the paper of Latchaw et al. [38]) depend on:

1. The different pre-determined end-points of operation: analgesia or hypalgesia. In the paper by Latchaw et al. [38], at 5 years relapses occurred in $26 \%$ of the patients in which the operation produced analgesia or anesthesia, in 54\% of patients in which it produced hypalgesia, and in $100 \%$ of patients in which no sensory deficits were caused.

2. The technical differences. Recurrence (particularly early relapses) can be due to an approximate technique. Performed by a skilled operator, TPRT allows the precise location of the cannula within the retrogasserian division and the lesion can be accurately confined. TPRT is relatively time consuming: it takes up to 2 hours and must be performed according to the following operative steps [51]:

(a) Identification by fluoroscopy in oblique projection of the sector of the oval foramen (the medial third for trigeminal division I-II and the middle third for III): this step takes only a few minutes;

(b) Localization of the trigeminal cistern (this structure can be more or less deeply located depending on the length of the mandibular branch);

(c) Electrophysiological identification of the target (this step is time consuming because at any attempt the operator must wait for the patient to awake prior to stimulation and for subsequent sedation prior to moving the electrode);

(d) Progressive thermolesion and verification of the obtained pin prick hypalgesia-analgesia.

The different percentages of recurrence after MVD (from 6\% in the study of Klun [52] and of Sindou and Mertens [53] to $47 \%$ in the study of Burchiel et al. [40]), apart from the operator's different technical experience, can reflect the different criteria in the selection of the patients or, merely, the casual inclusion of patients with or without true NVC.

If one considers the different surgical risks (operative death of MVD is 20-times greater than that of TPRT), $21 \%$ of recurrence after MVD can be regarded as a disappointing outcome in comparison with $24.4 \%$ after TPRT. The recurrence rate after MVD is so high that terms such as "failed microvascular decompression" [54-56] and "failed posterior fossa exploration" [57] were coined. In order to define indications for MVD, we must explain if MVD is the etiologic and definitive treatment for TN and if it really does not provoke facial sensory impairments nor postoperative dysesthesia.

Is MVD the etiologic treatment for TN?

MVD is the etiologic treatment when NVC occurs. Nevertheless, whereas most TN patients have NVC, some do not $[24,58]$. Moreover, NVC is a common finding in asymptomatic patients [59], in some TN patients it is contralateral to the pain [60] and, finally, many nerve roots are physiologically in contact with arteries and veins in the skull [61]. In order to make clear the concept of NVC and to study its pathogenetic role, the papers of Hardy and Rhoton [59] and Haines et al. [58] are quoted. Hardy and Rhoton bilaterally examined the trigeminal roots in 25 corpses of subjects who never had TN. They found that in 30 of 50 nerves, there was contact between an artery and the trigeminal root: 26 of the contacts were with the superior cerebellar artery (SCA) and 4 were with the antero-inferior cerebellar artery (AICA). Quoting this study, Adams and Chir [61] observed that arterial loop and neurovascular contact were present at least on one side in every examined subject and that as "each patient had a vessel in contact with one or other trigeminal nerve ... one can conclude that it is unusual not to find some 
vascular contact in asymptomatic patient at or near the root entry zone". In other words, arterial loop and neurovascular contact seem to be physiological. Haines et al. [58] examined 80 corpses: 40 without and 40 with a history of TN. These authors found, respectively, neurovascular contact and compression in $48 \%$ and $10 \%$ of the subjects without $\mathrm{TN}$ and in $28 \%$ and $80 \%$ of the subjects with TN. They concluded that arterial loop and neurovascular contact are common but cause TN only if the vessel exerts a "significant compression" on the root. At surgical exploration the root is "distorted" and shows a groove where the artery pulses. Piatt and Wilkins $[62,63]$ verified clinically these anatomical findings and correlated the surgical outcome with the nerve-vascular relation type. They found that MVD cured $\mathrm{TN}$ in $83 \%, 62 \%$ and $42 \%$ of the cases if, respectively, distortion of the root by an artery, contact of the root with an artery without distortion or contact-distortion of the root with a vein were present. Hence, the type of neurovascular relationship is crucial and arterial loop and neurovascular contact are to be distinguished by the compression and distortion of the root (or NVC). The latter has pathogenetic relevance whereas the simple arterial loop and neurovascular contact are unimportant anatomical abnormalities. Of the same opinion were Niwa et al. [64] who pointed out the difference between contact which is asymptomatic and compression which is symptomatic. Moreover, as NVC is not present in every TN patient, it is not the only cause of "essential" TN but one of the possible causes [65]. As demyelination is constantly present in every patient, natural aging can figure among the other causes of neuralgia [66].

Is MVD the definitive treatment for TN?

MVD is the definitive treatment for TN if there is NVC and there is not a severe neuropathic lesion of trigeminal root. Recurrence can be ascribed to the postoperative fibrotic adhesions formed around the nerve [56], to the intrinsic lesion [67] and especially to the absence of NVC.

\section{Does MVD not provoke facial sensory impairments?}

Facial sensory impairment occurred in an average of $8.9 \%$ of all patients treated with MVD and in $20 \%$ in the series of Burchiel et al. [40]. Searching for corneal sensitivity after neurosurgical interventions on the trigeminal nerve, Ackermann-Kaorner and Draeger [68] found that MVD may lead to a severe decrease of corneal sensitivity. In terms of complications concerning sensory loss of cornea, TPRT was the less risky treatment, followed by RGI, MVD and retro- gasserian rhizotomy according to Frazier [69]. Hence, it seems a hazard to guarantee patients that MVD does not cause sensory deficits: nevertheless, severe dysesthesia is an unusual complication.

\section{Selection of patients}

It is current opinion that TPRT has an established place because of its safety, particularly in elderly patients, and that MVD has an appeal in younger patients [70-76] because of its non-destructive nature. However, there are presently no clear guidelines for the choice of percutaneous or open operation. In order to establish such guidelines, it is crucial to preoperatively distinguish NVC from the innocent arterial loop and neurovascular contact and to recognize the type (reversible or irreversible) of intrinsic nerve lesion. The preoperative distinction between NVC and arterial loop was difficult in the past because angiography and computed tomography (CT) showed the arterial loop and neurovascular contact but not the size of compression. At operation, Tew et al. [60] found a "significant" impingement in less than half of 50 patients in whom preoperative study showed arterial loop and neurovascular contact. Fortunately, today magnetic resonance imaging (MRI) is a reliable technique to study neurovascular interaction at the trigeminal root entry zone [64, 77-93] and it must be performed in every TN patient candidate to MVD. Meaney et al. [86], sustaining that MRI is "an extremely sensitive and specific method for demonstrating vascular compression in TN", concluded that "open surgical procedures can be recommended with confidence".

Allowing the choice of MVD only at the presence of a demonstrated nerve compression, we can expect that the accuracy in the identification of NVC with MRI will reduce the percentage of postoperative failures and recurrence. Today, it is possible to demonstrate NVC but unfortunately there is no available method to preoperatively recognize the reversibility or irreversibility of the intrinsic nerve lesion in $\mathrm{TN}$ and consequently to identify the patients who surely will improve after MVD. This uncertain diagnosis remains the most frequent cause of failure, because if there is irreversible nerve damage, decompression does not ameliorate the symptoms and neurolesion is the only available treatment.

MVD is a successful operation when the indication is correct. Probably, many failures and relapses are the consequence of an inadequate selection of patients, after operations performed on the presumption that MVD is in any case the ideal cure for TN. With the availability of MRI, it can be stated that MVD is not an alternative of percutaneous techniques, favorable if the patients can tolerate a major opera- 
tion: it has firm indications (Fig. 1) and the diatribe between the supporters of percutaneous techniques and MVD can be concluded with the following statements: (1) percutaneous techniques are indicated for patients without demonstrated NVC (including patients with TN-MS) and in those with NVC if MVD is contraindicated by a concomitant illness or is refused by the informed patient, and (2) MVD is indicated in patients with ascertained NVC, without severe trigeminal neuropathy and in good health who, informed of the surgical risk, favor this operation desiring no sensory deficit and hoping to be among the more than $80 \%$ subjects who have no postoperative sensory deficits.

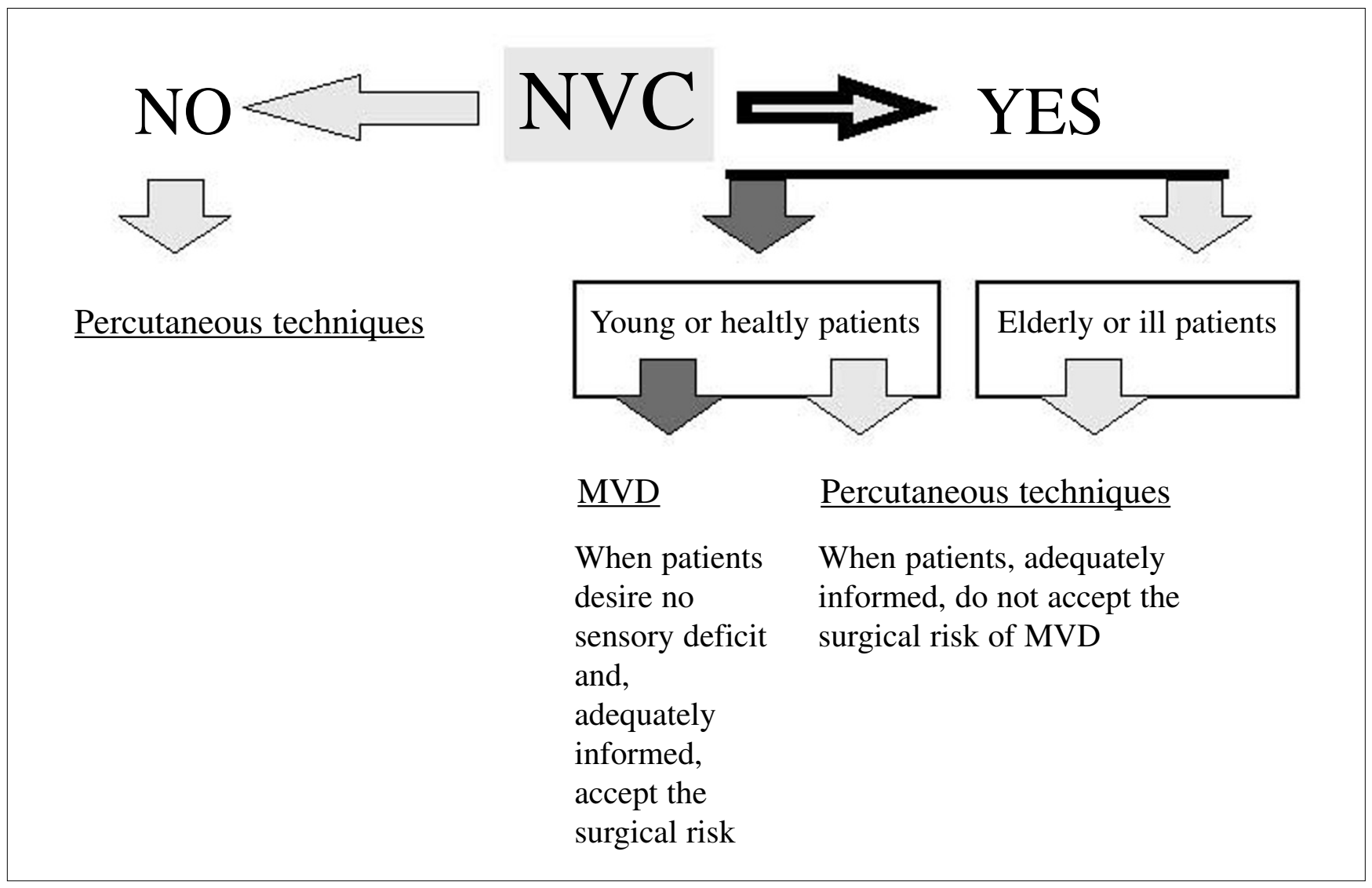

Fig. 1 Choice of open or percutaneous surgical procedures for trigeminal neuralgia. $N V C$, neurovascular conflict; $M V D$, microvascular decompression

\section{References}

1. Loeser JD (1984) Tic douloureux and atypical facial pain. In: Wall PD, Melzack R (eds) Textbook of pain. Churchill Livingstone, Edinburgh London Melbourne New York, pp 426-434

2. Sweet WH, Wepsic JC (1974) Controlled thermocoagulation of trigeminal ganglion and rootlets for differential destruction of pain fibres. J Neurosurg 39:143-156
3. Hakanson S (1981) Trigeminal neuralgia treated by injection of glycerol into the trigeminal cistern.

Neurosurgery 9:638-646

4. Mullan S, Lichtor T (1983)

Percutaneous microcompression of the trigeminal ganglion for trigeminal neuralgia. J Neurosurg 59:1007-1012

5. Dandy WE (1925) Section of the sensory root of the trigeminal nerve at the pons. Bull Johns Hopkins Hosp 36:105-106
6. Jannetta PJ (1976) Microsurgical approach to the trigeminal nerve for tic douloureux. Prog Neurol Surg 7:180-200

7. Barker FG, Jannetta PJ, Bissonette DJ, Larkins MV, Jho HD (1966) The long-term outcome of microvascular decompression for trigeminal neuralgia. N Engl J Med 334:1077-1083

8. Goldhahn WE (1985) Experiences with the Janetta operation in patients with trigeminal neuralgia. Zentralbl Neurochir 46:233-242 
9. Kunze S, Steiner HH (1987) Trigeminal neuralgia. Results of microsurgical parapontine decompression. Nervenarzt 58:33-39

10. Lovely TJ, Jannetta PJ (1997) Microvascular decompression for trigeminal neuralgia. Surgical technique and long-term results. Neurosurg Clin N Am 8:11-29

11. Meneses MS, Clemente R, Russ HH, Ramina R, Pedrozo AA, Hunhevicz S, Favorito LF (1995) Microsurgical treatment of trigeminal neuralgia. A study of 50 cases. Neurochirurgie 41:349-352

12. Niemeyer Filho P (1983) Neurovascular decompression in trigeminal neuralgia. Analysis of 70 cases. Arq Neuropsiquiatr 41:321-331

13. Turgut M, Benli K, Ozgen T, Saglam S, Bertan V, Erbengi A (1996) Twenty-five years experience in the treatment of trigeminal neuralgia. Comparison of three different operative procedures in forty-nine patients. J Craniomaxillofac Surg 24:40-45

14. Zorman G, Wilson CB (1984) Outcome following microsurgical vascular decompression or partial sensory rhizotomy in 125 cases of trigeminal neuralgia. Neurology 34:1362-1365

15. Frank F, Gaist T, Fabrizi A, Cohadon F, Laporte A, Sedan R, Peragut JC, Sethian M, Sturiale C (1985) Results of percutaneous selective thermocoagulation of Gasser's ganglion in essential facial neuralgia. Synthesis of results obtained in 939 treated patients. Neurochirurgie 31:179-182

16. Motta P, De Souza MT, Sengupta RP (1980) Radiofrequency-thermocoagulation in the treatment of trigeminal neuralgia: analysis of 100 cases. Arq Neuropsiquiatr 38:33-44

17. Ogleznev Kia, Grigorian IuA (1989) Differentiated high-frequency rhizotomy in trigeminal neuralgia. $\mathrm{Zh}$ Vopr Neirokhir Im NN Burdenko 2:38-41

18. Oturai AB, Jensen K, Eriksen J, Madsen F (1996) Neurosurgery for trigeminal neuralgia: comparison of alcohol block, neurectomy, and radiofrequency coagulation. Clin $\mathrm{J}$ Pain 12:311-315
19. Pertuiset B, Philippon J, Nachanakian A, Van Effenterre R (1977) The treatment of trigeminal neuralgia by retrogasserian differential electrodiathermy. One hundred cases (author's transl). Nouv Presse Med 6:3717-3720

20. Philippon J, Nachanakian A, Rivierez M, Horn YE (1980) Gasserian differential thermocoagulation in trigeminal neuralgia: a medium-term follow up. Rev Neurol (Paris) 136:763-768

21. Sweet WH (1988) Percutaneous methods for the treatment of trigeminal neuralgia and other faciocephalic pain; comparison with microvascular decompression. Semin Neurol 8:272-279

22. Sweet WH (1986) The treatment of trigeminal neuralgia (tic douloureux). N Engl J Med 315:174-177

23. Tew JM Jr, Lockwood P, Mayfield FH (1975) Treatment of trigeminal neuralgia in the aged by a simplified surgical approach (percutaneous electrocoagulation). J Am Geriatr Soc 23:426-430

24. Van Loveren H, Tew JM, Keller JT, Nurre MA (1982) A 10-year experience in the treatment of trigeminal neuralgia. Comparison of percutaneous stereotaxic rhizotomy and posterior fossa exploration. J Neurosurg 57:757-764

25. Jannetta PJ (1991) Surgical treatment: microvascular decompression. In: Fromm GH, Sessle BJ (eds) Trigeminal neuralgia. ButterworthHeinemann, Boston London Singapore Sydney Toronto Wellington, pp 145-157

26. Isu T, Abe H, Nakagawa Y, Aida T, Tsuru M, Ito T, Murai H (1983) Surgical management of trigeminal neuralgia, hemifacial spasm, paroxysmal tinnitus and nystagmus by neurovascular decompression. Hokkaido Igaku Zasshi 58:587-599

27. Isu T, Abe H, Nakagawa Y, Mitsumori K, Nakagawa T, Sakuragi M, Tsuru M, Ito T (1985) Surgical treatment of trigeminal neuralgia: neurovascular decompression established by Jannetta. Hokkaido Igaku Zasshi 60:91-96

28. Burchiel KJ, Steeg TD, Howe JF, Loeser JD (1981) Comparison of percutaneous radiofrequency gangliolysis and microvascular decompression for the surgical menagement of tic douloureux. Neurosurgery 9:111-119
29. Möbius E, Leopold HC, Paulus WM (1984) Treatment of typical trigeminus neuralgias. Overview of the current state of drug and surgical therapy. Fortschr Med 102:935-939

30. Walchenbach R, Voormolen JH, Hermans J (1994) Microvascular decompression for trigeminal neuralgia: a critical reappraisal. Clin Neurol Neurosurg 96:290-295

31. Morley TP (1985) Case against microvascular decompression in the treatment of trigeminal neuralgia. Arch Neurol 42:801-802

32. Soyka D (1990) Etiology and therapy of trigeminal neuralgia.

Neurochirurgia (Stuttg) 33[Suppl 1]:11-13

33. Taha JM, Tew JM Jr (1996) Comparison of surgical treatments for trigeminal neuralgia: reevaluation of radiofrequency rhizotomy. Neurosurgery 38:865-871

34. Taha JM, Tew JM Jr (1997) Treatment of trigeminal neuralgia by percutaneous radiofrequency rhizotomy. Neurosurg Clin N Am 8:31-39

35. Broggi G, Franzini A, Giorgi C, Servello D, Brock S (1993) Trigeminal neuralgia: new surgical strategies. Acta Neurochir Suppl (Wien) 58:171-173

36. Kaplan EL, Meier P (1958) Nonparametric estimation from incomplete observations. J Am Stat Assoc 53:457-481

37. Meglio M, Cioni B (1989) Precutaneous procedures for trigeminal neuralgia: microcompression versus radiofrequency thermocoagulation. Personal experience. Pain 38:9-16

38. Latchaw JP, Hardy RW, Forsythe SB, Cook AF (1983) Trigeminal neuralgia treated by radiofrequency coagulation. J Neurosurg 59:479-484

39. Ischia S, Luzzani A, Polati E and Ischia A (1990) Percutaneous controlled thermocoagulation in the treatment of trigeminal neuralgia. Clin J Pain 6:96-104

40. Burchiel KJ, Clarke H, Haglund M, Loeser JD (1988) Long-term efficacy of microvascular decompression in trigeminal neuralgia. J Neurosurg 69:35-38

41. Fritz W, Schafer J, Klein HJ (1988) Hearing loss after microvascular decompression for trigeminal neuralgia. J Neurosurg 69:367-370 
42. Fuse T, Miller MB (1996) Delayed and progressive hearing loss after microvascular decompression of cranial nerves. Ann Otol Rhinol Laryngol 105:158-161

43. Schvarcz JR (1982) Percutaneous thermocontrolled differential retrogasserian rhizotomy for idiopathic trigeminal neuralgia. Acta Neurochir 64:51-58

44. Chen HJ, Lui CC (1995) Peduncular hallucinosis following microvascular decompression for trigeminal neuralgia: report of a case. J Formos Med Assoc 94:503-505

45. Tsukamoto H, Matsushima T, Fujiwara S, Fukui M (1993) Peduncular hallucinosis following microvascular decompression for trigeminal neuralgia: case report. Surg Neurol 40:31-34

46. Siegfried J (1978) Neurosurgical treatment of symptomatic and atypical facial neuralgias. Muench Med Wochenschr 120:675-678

47. Brisman R (1987) Trigeminal neuralgia and multiple sclerosis. Arch Neurol 44:379-381

48. Broggi G, Franzini A (1982)

Radiofrequency trigeminal rhizotomy in treatment of symptomatic non-neoplastic facial pain. J Neurosurg 57:483-486

49. Resnick DK, Jannetta PJ, Lunsford LD, Bissonette DJ (1996)

Microvascular decompression for trigeminal neuralgia in patients with multiple sclerosis. Surg Neurol 46:358-361

50. Sindou M, Amrani F, Mertens $P$ (1990) Microsurgical vascular decompression in trigeminal neuralgia. Comparison of 2 technical modalities and physiopathologic deductions. A study of 120 cases. Neurochirurgie 36:16-25

51. Orlandini G (1996) Interventi sul trigemino. In: Orlandini G (ed) Manuale di chirurgia percutanea del dolore. Edizioni Medico Scientifiche, Pavia, pp 141-189

52. Klun B (1992) Microvascular decompression and partial sensory rhizotomy in the treatment of trigeminal neuralgia: personal experience with 220 patients. Neurosurgery 30:49-52
53. Sindou M, Mertens P (1993) Microsurgical vascular decompression (MVD) in trigeminal and glossovago-pharyngeal neuralgias. A twenty-year experience. Acta Neurochir Suppl (Wien) 58:168-170

54. Cho DY, Chang CG, Wang YC, Wang FH, Shen CC, Yang DY (1994) Repeat operations in failed microvascular decompression for trigeminal neuralgia. Neurosurgery 35:665-669

55. Rath SA, Klein HJ, Richter HP (1996) Findings and long-term results of subsequent operations after failed microvascular decompression for trigeminal neuralgia. Neurosurgery 39:933-938

56. Yamaki T, Hashi K, Niwa J, Tanabe S, Nakagawa T, Nakamura T, Uede T, Tsuruno T (1992) Results of reoperation for failed microvascular decompression. Acta Neurochir (Wien) 115:1-7

57. Bederson JB, Wilson CB (1989) Evaluation of microvascular decompression and partial sensory rhizotomy in 252 cases of trigeminal neuralgia. J Neurosurg 71:359-367

58. Haines SJ, Jannetta PJ, Zorub DS (1980) Microvascular relations of the trigeminal nerve. An anatomical study with clinical correlation. $\mathbf{J}$ Neurosurg 52: 381-386

59. Hardy DG, Rhoton AL (1978) Microsurgical relationship of the superior cerebellar artery and the trigeminal nerve. J Neurosurg 49:669-678

60. Tew JM, Van Loveren H, Keller JT, Nurre MA (1983) A 10-year experience in the treatment of trigeminal neuralgia: a comparison of percutaneous stereotaxic rhizotomy and posterior fossa exploration. In: Rizzi R, Visentin M (eds) Pain therapy. Elsevier Biomedical, Amsterdam New York Oxford, pp 321-337

61. Adams CBT, Chir M (1989) Microvascular compression: an alternative view and hypothesis. $\mathbf{J}$ Neurosurg 57:1-12

62. Piatt JH, Wilkins RH (1984) Microvascular decompression for tic douloureux. Neurosurgery 15:456

63. Piatt JH, Wilkins RH (1984) Treatment of tic douloureux and hemifacial spasm by posterior fossa exploration. Therapeutic implications of various neurovascular relationships. Neurosurgery 14:462-471
64. Niwa Y, Shiotani M, Karasawa H, Ohseto K, Naganuma Y (1996) Identification of offending vessels in trigeminal neuralgia and hemifacial spasm using SPGR-MRI and 3DTOF-MRA. Rinsho Shinkeigaku 36:544-550

65. Sindou MP, Chiha M, Mertens P (1994) Anatomical findings observed during microsurgical approaches of the cerebellopontine angle for vascular decompression in trigeminal neuralgia (350 cases). Stereotact Funct Neurosurg 63:203-207

66. Suwa H, Hanakita J, Mizuno M, Namura S, Ohtsuka T, Asahi M, Li W, Kondoh A (1993) Long-term follow up of trigeminal neuralgic patients treated by retrogasserian rhizotomy or by microvascular decompression. No Shinkei Geka 21:29-36

67. Sun T, Saito S, Nakai O, Ando T (1994) Long-term results of microvascular decompression for trigeminal neuralgia with reference to probability of recurrence. Acta Neurochir (Wien) 126:144-148

68. Ackermann-Kaorner M, Draeger J (1991) Quantitative determination of corneal sensitivity in idiopathic trigeminal neuralgia and after neurosurgical interventions on the trigeminal nerve. Klin Monatsbl Augenheilkd 199:84-90

69. Frazier CH (1918) A surgeon's impression of trigeminal neuralgia based on experiences with three hundred and two cases. JAMA 70:1345-1350

70. Ferguson GG, Brett DC, Peerless SJ, Barr HW, Girvin JP (1981)

Trigeminal neuralgia: a comparison of the results of percutaneous rhizotomy and microvascular decompression. Can J Neurol Sci 8:207-214

71. Grunert P, Pendl G, Oztürk E, Ungersböck K, Czech T (1988) Results of electrocoagulation of Gasser's ganglion in 250 patients with idiopathic trigeminal neuralgia. Zentralbl Neurochir 49:196-201

72. Probst C (1991) Neurosurgery in old age. II: CNS tumors, cerebrospinalvascular diseases, pain surgery, conclusions. Schweiz Rundsch Med Prax 80:1396-1411 
73. Rappaport ZH (1996) The choice of therapy in medically intractable trigeminal neuralgia. Isr J Med Sci 32:1232-1234

74. Sano K (1987) Neurosurgical treatments of pain: a general survey. Acta Neurochir Suppl (Wien) 38:86-96

75. Tarlov E (1980) Percutaneous and open microsurgical techniques for relief of refractory tic douloureux. Surg Clin North Am 60:593-607

76. Voorhies R, Patterson RH (1981) Management of trigeminal neuralgia (tic douloureux). JAMA 245:2521-2523

77. Darlow LA, Brooks ML, Quinn PD (1992) Magnetic resonance imaging in the diagnosis of trigeminal neuralgia. $\mathrm{J}$ Oral Maxillofac Surg 50:621-626

78. Gybels JM, Sweet WH (1989) The trigeminal nerve. In: Gybels JM, Sweet WH (eds) Neurosurgical treatment of persistent pain. Karger, Basel, pp 10-69

79. Hosoya T, Watanabe N, Yamaguchi K, Saito S, Nakai O (1995) Threedimensional-MRI of neurovascular compression in patients with hemifacial spasm. Neuroradiology 37:350-352

80. Korogi Y, Nagahiro S, Du C, Sakamoto Y, Takada A, Ushio Y, Ikushima I, Takahashi M (1995) Evaluation of vascular compression in trigeminal neuralgia by $3 \mathrm{D}$ timeof-flight MRA. J Comput Assist Tomogr 19:879-884

81. Kumon Y, Sakaki S, Kohno K, Ohta S, Ohue S, Miki H (1997) Three dimensional imaging for presentation of the causative vessels in patients with hemifacial spasm and trigeminal neuralgia. Surg Neurol 47:178-184

82. Magnaldi S, Cecconi P, Skrap M, Ricci C, Cova MA, Pozzi-Mucelli RS (1992) Magnetic resonance in trigeminal neuralgia. Radiol Med (Torino) 83:700-705

83. Masur H, Papke K, Bongartz G, Vollbrecht K (1995) The significance of three-dimensional MR-defined neurovascular compression for the pathogenesis of trigeminal neuralgia. J Neurol 242:93-98

84. Matsumoto S, Kishikawa T, Kudo S, Matsuo Y, Totoki T, Harano K (1991) Magnetic resonance imaging of idiopathic trigeminal neuralgia. Nippon Igaku Hoshasen Gakkai Zasshi 51:91-93
85. Matsumoto S, Kishikawa T, Kudo S, Matsuo Y, Totoki T, Harano K (1991) Magnetic resonance imaging of idiopathic trigeminal neuralgia. Nippon Igaku Hoshasen Gakkai Zasshi 51:91-93

86. Meaney JF, Eldridge PR, Dunn LT, Nixon TE, Whitehouse GH, Miles JB (1995) Demonstration of neurovascular compression in trigeminal neuralgia with magnetic resonance imaging. Comparison with surgical findings in 52 consecutive operative cases. $\mathbf{J}$ Neurosurg 83:799-805

87. Nomura T, Ikezaki K, Matsushima T, Fukui M (1994) Trigeminal neuralgia: differentiation between intracranial mass lesions and ordinary vascular compression as causative lesions. Neurosurg Rev 17:51-57

88. Sens MA, Higer HP (1991) MRI of trigeminal neuralgia: initial clinical results in patients with vascular compression of the trigeminal nerve. Neurosurg Rev 14:69-73

89. Tash RR, Sze G, Leslie DR (1989) Trigeminal neuralgia: MR imaging features. Radiology 172:767-770

90. Tien RD, Wilkins RH (1993) MRA delineation of the vertebral-basilar system in patients with hemifacial spasm and trigeminal neuralgia. AJNR Am J Neuroradiol 14:34-36

91. Umehara F, Kamishima K, Kashio N, Yamaguchi K, Sakimoto T, Osame M (1995) Magnetic resonance tomographic angiography: diagnostic value in trigeminal neuralgia. Neuroradiology 37:353-355

92. Wong BY, Steinberg GK, Rosen L (1989) Magnetic resonance imaging of vascular compression in trigeminal neuralgia. Case report. J Neurosurg 70:132-134

93. Yang J, Simonson TM, Ruprecht A, Meng D, Vincent SD, Yuh WT (1996) Magnetic resonance imaging used to assess patients with trigeminal neuralgia. Oral Surg Oral Med Oral Pathol Oral Radiol Endod 81:343-350

94. Siegfried J (1981) Percutaneous controlled thermocoagulation of gasserian ganglion in trigeminal neuralgia. Experience with 1000 cases. In: Samii M, Jannetta PJ (eds) The cranial nerves. Springer, Berlin Heidelberg New York, pp 322-330
95. Mittal B, Thomas DG (1986) Controlled thermocoagulation in trigeminal neuralgia. J Neurol Neurosurg Psychiatry 49:932-936

96. Piquer J, Joanes V, Roldan P, BarciaSalorio JL, Masbout G (1987) Longterm results of percutaneous gasserian ganglion lesions. Acta Neurochir Suppl 39:139-141

97. Fraioli B, Esposito V, Guidetti B, Cruccu G, Manfredi M (1989) Treatment of trigeminal neuralgia by thermocoagulation, glycerolization and percutaneous compression of the gasserian ganglion and/or retrogasserian rootlets: long-term results and therapeutic protocol.

Neurosurgery 24:239-245

98. Frank F and Fabrizi AP (1989) Percutaneous surgical treatment of trigeminal neuralgia. Acta Neurochir (Wien) 97:128-130

99. Broggi G, Franzini A, Lasio G, Giorgi C and Servello D (1990) Long term results of percutaneous retrogasserian thermorhizotomy for "essential" trigeminal neuralgia: considerations in 1000 consecutive patients. Neurosurgery 26:783-786

100. Nugent GR (1991) Surgical treatment: radiofrequency gangliolysis and rhizotomy. In: Fromm GH, Sessle BJ (eds) Trigeminal neuralgia. Butterworth-Heinemann, Boston London Singapore Sydney Toronto Wellington, pp 159-184

101. Moraci A, Buonaiuto C, Punzo A, Parlato C, Amalfi R (1992) Trigeminal neuralgia treated by percutaneous thermocoagulation. Comparative analysis of percutaneous thermocoagulation and other surgical procedures. Neurochirurgia (Stuttg) 35:48-53

102. Sanders M, Henny CP (1992) Results of selective percutaneous controlled radiofrequency lesion for treatment of trigeminal neuralgia in 240 patients. Clin J Pain 8:23-27

103. Belpietro M, Lenzi A (1995) Percutaneous retrogasserian thermorhizotomy in the treatment of trigeminal neuralgia: a study of 175 patients. Int J Pain Ther 5:45-56

104. Taha JM, Tew JMJr, Buncher CR (1995) A prospective 15-year follow up of 154 consecutive patients with trigeminal neuralgia treated by percutaneous stereotactic radiofrequency thermal rhizotomy. J Neurosurg 83:989-993 
105. Apfelbaum RI (1984) Surgery for tic douloureux. Clin Neurosurg 31:351-365

106. Barba D, Alksne JF (1984) Success of microvascular decompression with and without prior surgical therapy for trigeminal neuralgia. J Neurosurg 60:104-107
107. Kolluri S, Heros RC (1984) Microvascular decompression for trigeminal neuralgia. A five-year follow-up study. Surg Neurol 22:235-240

108. Dahle L, Von Essen C, Kourtopulos H, Ridderheim PA, Vavruch L (1989) Microvascular decompression for trigeminal neuralgia. Acta Neurochir (Wien) 99:109-112
109. Mendoza N, Illingworth RD (1995) Trigeminal neuralgia treated by microvascular decompression: a long-term follow-up study. Br J Neurosurg 9:13-19 